\title{
Samenwerken met Veilig Thuis: wat gaat goed en wat kan er beter?
}

\author{
Anne Custers · Laurien Oosterwijk · Paul Beker · Thea van Zeben-van der Aa
}

Published online: 25 January 2019

(c) The Author(s) 2019

Samenvatting Bij een vermoeden van kindermishandeling moeten medische professionals (MP's) handelen conform het stappenplan uit de KNMG-meldcode huiselijk geweld en kindermishandeling. Uit de registratie van Veilig Thuis (VT) blijkt dat MP's weinig meldingen van kindermishandeling doen. Zowel terughoudendheid vanwege persoonlijke barrières als de kwaliteit van de samenwerking met VT lijkt hierbij een rol te spelen. In dit onderzoek hebben wij deze samenwerking geanalyseerd, met als doel deze te verbeteren. Verder zijn de ervaringen van MP's met het signaleren van kindermishandeling en hun handelen daarbij in kaart gebracht. Via online vragenlijsten werden 623 MP's en alle 13 medewerkers van VT Zuid-Limburg benaderd. Het responspercentage was respectievelijk $20 \%$ en $87 \%$. MP's gaven aan behoefte te hebben aan meer kennis over VT, naast een 24/7bereikbaarheid. VT-medewerkers vonden de bereikbaarheid van MP's en kennis van zowel de KNMGmeldcode als de taken en functies van VT de belangrijkste verbeterpunten. Op basis van de resultaten werd een structureel overleg tussen MP's en VT-medewerkers geïnitieerd, met als einddoel verlaging van de drempel om contact op te nemen met VT. Daarnaast zal regionale scholing georganiseerd worden die beter aansluit bij de wensen van MP's.

Trefwoorden kindermishandeling - samenwerking • medische professionals - Veilig Thuis · meldcode . huisarts · jeugdarts · kinderarts · kinderneuroloog

A. Custers $(\bowtie) \cdot$ L. Oosterwijk $\cdot$ Dr. T. van Zeben-van der Aa Afdeling Kindergeneeskunde, Maastricht Universitair Medisch Centrum, Maastricht, Nederland

anne.custers@mumc.nl

P. Beker

Veilig Thuis, GGD Zuid-Limburg, Heerlen, Nederland

\section{Collaboration with Safe at Home: what goes well and what can be improved?}

Abstract Despite the introduction of the reporting code on domestic violence and child abuse in the Netherlands, physicians seem to under-report child abuse. Individual barriers as well as the quality of collaboration with the Advice and Reporting Centers for Domestic Violence and Child Abuse (Veilig Thuis, VT) may play an important role. This study was designed in order to gain insight in this collaboration and to develop a best practice to improve it. A second aim is to investigate personal experiences with signaling and dealing with child abuse. An online questionnaire was sent to employees of VT (VTE's, $n=13$ ) and physicians that work with children $(n=623)$ in South Limburg. Respectively 13 (87\%) and 128 individuals (20\%) completed the questionnaire. Physicians indicate the need for more information about VT, and a 24/7 service. VTE's indicate that both the availability of physicians and their knowledge of the reporting code and tasks of VT could be optimized. Based on the results, a regular meeting with general practitioners, preventive health care doctors and VTE's is initiated to learn about each other's responsibilities, experiences and mutual expectations. In addition, regional training will be organized for all physicians.

Keywords Child abuse - Collaboration · Physicians · Advice and Reporting Center for Domestic Violence and Child Abuse - Reporting code - General practitioner - Child and adolescent health care doctor - Pediatrician $\cdot$ pediatric neurologist 


\section{Kernpunten}

- Ondanks de Wet verplichte meldcode huiselijk geweld en kindermishandeling en het bestaan van een meldrecht nemen medische professionals (MP's) nog steeds weinig contact op met Veilig Thuis (VT).

- MP's hebben behoefte aan meer inhoudelijke kennis over VT en kindermishandeling. Daarnaast dringen zij aan op een 24/7-bereikbaarheid van VT.

- VT noemt de wisselende bereikbaarheid van MP's en hun soms gebrekkige kennis over de KNMG-meldcode en de taken en verantwoordelijkheden van VT als struikelbok in de communicatie.

- Om tot betere samenwerking te komen is er in Zuid-Limburg een regionaal regulier overleg tussen MP's en VT geïnitieerd, naast aanvullende scholing van MP's.

\section{Inleiding}

Bij vermoedens van kindermishandeling of huiselijk geweld dient iedere arts het stappenplan uit de KNMG-meldcode te volgen, zoals verplicht is door de Wet verplichte meldcode huiselijk geweld en kindermishandeling uit 2013 [1]. De arts heeft zoals iedere beroepskracht met een beroepsgeheim of zwijgplicht een wettelijk meldrecht [2]. Dit houdt in dat deze ook zonder toestemming van de betrokkene of zijn ouders een melding kan doen bij Veilig Thuis (VT). Doel van een melding is een vermoeden te onderzoeken - de melder hoeft er niet zeker van te zijn dat er sprake is van huiselijk geweld of kindermishandeling. De eerste meldcode voor artsen van de Koninklijke Nederlandsche Maatschappij tot bevordering der Geneeskunst (KNMG) stamt uit 2003 en vormt de professionele norm voor artsen bij het maken van de afweging wanneer, bij wie en volgens welke stappen te handelen [3]. Een verplichte meldcode is iets anders dan een meldplicht. Het is aan de professionals om te beslissen of ze hun vermoeden van huiselijk geweld of kindermishandeling wel of niet melden. Het stappenplan uit de meldcode biedt houvast bij het nemen van die beslissing.

Twee stappen uit de meldcode zijn cruciaal: stap 2, waarbij artsen bij een vermoeden van kindermishandeling verplicht zijn advies te vragen bij VT, en stap 5a en $5 b$, waarbij de arts besluit een casus zelf te monitoren (5a) of daadwerkelijk tot melding bij VT overgaat (5b). Ondanks de verplichting van stap 2 vragen weinig medische professionals (MP's) advies en wordt er vooral door huisartsen en jeugdartsen slechts incidenteel gemeld. Dit blijkt onder andere uit de cijfers van het voormalige Advies- en Meldpunt Kindermishandeling (AMK) [4]. In de regio van AMK ZuidLimburg zijn in 2014 in totaal 320 meldingen gedaan, waarvan respectievelijk zes afkomstig van huisartsen, drie afkomstig uit de jeugdgezondheidszorg (JGZ) en 46 van ziekenhuizen [4]. Uit landelijk onderzoek door de Inspectie Gezondheidszorg (IGZ) in 2010 en 2012 op huisartsenposten (HAP) blijkt dat de aandacht voor kindermishandeling achterblijft $[5,6]$. Met name de systematische screening op de HAP, de scholing van de triagisten en de samenwerking met het toenmalige AMK blijken verbeterpunten te zijn [6]. Vooral onbekendheid met het AMK/VT en persoonlijke barrières bij de potentiële melders blijken hierbij een rol te spelen. Voorbeelden hiervan zijn: de angst voor 'valse beschuldiging', angst voor een schending van de privacy van het gezin, angst voor een vertrouwensbreuk met de ouders of het kind, angst voor de woede van de ouders als zij te weten komen wie heeft gemeld en slechte ervaringen met eerdere meldingen [7-10].

\section{Onderzoek naar samenwerking tussen MP's en VT}

Op 1 januari 2015 heeft de transitie van de jeugdzorg naar de gemeenten plaatsgevonden [11]. Als gevolg van de nieuwe Jeugdwet en de Wet maatschappelijke ondersteuning (Wmo) zijn het AMK en het Steunpunt Huiselijk Geweld (SHG) op dat moment overgegaan in een AMHK (Advies- en Meldpunt Huiselijk Geweld en Kindermishandeling), dat landelijk de naam Veilig Thuis heeft gekregen. Er zijn momenteel 26 VT-regio's in Nederland. In Zuid-Limburg is VT onderdeel van de GGD Zuid-Limburg. De transitie was voor de provincie Limburg aanleiding om onderzoek te faciliteren naar de communicatie en samenwerking tussen MP's en VT in de regio Zuid-Limburg.

Het doel van ons onderzoek is het evalueren en verbeteren van deze samenwerking en de communicatie bij vermoedens en melding van kindermishandeling en huiselijk geweld. Op deze manier hopen we eventuele barrières in het contact met VT weg te nemen en het aantal contactmomenten te vergroten. Daarnaast hebben we persoonlijke ervaringen van MP's bij het signaleren van en handelen bij kindermishandeling en huiselijk geweld in kaart gebracht en wensen voor scholing geïnventariseerd.

\section{Methode}

Het onderzoek bestond uit een kwantitatief deel in de vorm van een online vragenlijst voor zowel MP's als VT-medewerkers, en een aanvullend kwalitatief deel dat een groepsinterview onder de VT-medewerkers betrof.

\section{Het kwantitatieve onderzoek}

In overleg met het onderzoeksteam en een klankbordgroep werden twee online vragenlijsten ontwikkeld voor MP's en VT-medewerkers in Zuid-Limburg. De eerste vragenlijst werd in mei 2015 gestuurd aan 506 huisartsen, 27 jeugdartsen $0-4$ jaar, 26 jeugdartsen 
Tabel 1 Responspercentages van de medische professionals

\begin{tabular}{|l|r|r|l|}
\hline & aantal benaderde artsen & aantal respondenten & \multicolumn{2}{l|}{ responspercentage } \\
\hline huisarts & 509 & 68 & 13 \\
\hline jeugdarts 0-4 jaar & 27 & 18 & 67 \\
\hline jeugdarts 4-18 jaar & 26 & 8 & 31 \\
\hline kinderarts & 52 & 28 & 54 \\
\hline spoedeisendehulparts & 6 & 4 & 67 \\
\hline kinderneuroloog & 6 & 2 & 33 \\
\hline totaal artsen & 626 & 128 & 20 \\
\hline
\end{tabular}

4-18 jaar, 52 kinderartsen, 6 spoedeisendehulpartsen en 6 kinderneurologen. De vragenlijst bestond uit 54 vragen over 1) ervaringen met het voormalige AMK in de periode vóór 2015,2 ) ervaringen met het huidige VT en 3) algemene vragen over de eigen beroepsgroep. In verband met het aanvankelijk zeer lage responspercentage van de huisartsen werd deze groep naast meerdere reminders per e-mail, ook nog via een brief benaderd met het verzoek de vragenlijst alsnog in te vullen.

De tweede vragenlijst werd in dezelfde periode verstuurd en was bestemd voor VT-medewerkers (10 maatschappelijk werkers, 2 gedragswetenschappers en 1 vertrouwensarts). De vragenlijst bestond uit 36 vragen over 1) de indruk die VT-medewerkers hebben van MP's op het gebied van kennis en signaleren van kindermishandeling, 2) de communicatie en samenwerking met MP's en 3) kwaliteiten en verbeterpunten van VT zelf.

\section{Analyse}

De gegevens zijn met behulp van SPSS (versie 21) geanalyseerd. Hiervoor zijn de MP's vanwege het kleine aantal respondenten in drie groepen geclusterd: huisartsen, jeugdartsen en medisch specialisten. De bevindingen van dit onderzoek werden beschreven en geïnterpreteerd op basis van univariate analyses. De uitkomsten zijn vanwege de lage aantallen indicatief.

\section{Het kwalitatieve onderzoek}

Op basis van de bevindingen uit het kwantitatieve onderzoek werd een gespreksleidraad opgesteld voor een groepsinterview met alle VT-medewerkers, dat in oktober 2015 plaatsvond. In dit interview werd ingegaan op 1) de opvallende bevindingen uit het kwantitatieve onderzoek en de mogelijke verklaringen hiervoor, 2) ervaringen uit de praktijk, 3) knelpunten in de samenwerking met MP's en 4) oplossingen om deze te verbeteren.

\section{Terugkoppeling}

Resultaten van het onderzoek zijn aan de verschillende groepen respondenten teruggekoppeld in de vorm van interactieve presentaties in de periode van maart tot en met december 2016. Hen werd onder an- dere gevraagd een toelichting te geven op een aantal opvallende resultaten.

\section{Resultaten}

\section{Medische professionals}

\section{Kenmerken van de onderzoekspopulatie}

De totale respons van MP's was 20\% (tab. 1). Gemiddeld waren de respondenten ruim achttien jaar werkzaam als arts, waarvan bijna veertien jaar binnen de huidige functie. De huisartsen waren werkzaam op diverse plekken verspreid over Zuid-Limburg. De medisch specialisten waren zowel werkzaam in het academisch ziekenhuis (65\%), als in de niet-academische ziekenhuizen (35\%).

\section{Overzicht van de aantallen}

Bijna alle respondenten bleken in het voorgaande jaar vermoedens te hebben gehad van kindermishandeling (93\%). Jeugdartsen bleken bij zorgen het vaakst zelf hulp te initiëren, gevolgd door huisartsen (respectievelijk 92 en 88\%). Medisch specialisten schakelden minder vaak zelf hulp in en deden als zij daartoe toch besloten in $90 \%$ van de gevallen alsnog een melding bij VT. Vierentwintig huisartsen (35\%), 7 jeugdartsen (29\%) en 23 medisch specialisten (73\%) gaven aan dat zij in 2014 een melding hadden gedaan bij 1 of meer kinderen.

De vorm van kindermishandeling waarover een melding werd gedaan verschilde per groep artsen. Huisartsen meldden veelal (getuige te zijn van) huiselijk geweld, verwaarlozing of lichamelijke mishandeling (respectievelijk 46\%, 42\% en 38\%). Bij jeugdartsen ging het voornamelijk om verwaarlozing (86\%) of lichamelijke mishandeling (43\%) en bij medisch specialisten om lichamelijke mishandeling (87\%). Er waren duidelijke verschillen te zien in de redenen om te melden (zie fig. 1).

In een aantal gevallen werd afgezien van een melding omdat de melding reeds door een andere partij was gedaan, er twijfels waren over de eigen inschatting en beoordeling, respondenten vreesden de patiënt kwijt te raken, er onvoldoende vertrouwen in het AMK was of respondenten de meldingsprocedures als te complex ervoeren. Het invoeren van een meldplicht zou niet leiden tot meer meldingen, aldus de respondenten. 
Figuur 1 Redenen van medische professionals om een melding te doen bij het AMK (meerdere antwoorden mogelijk)
De ingezette hulp was niet voldoende in dit gezin

Problematiek te complex om zelf mee aan de slag te gaan Er was sprake van fysiek letsel

Er was sprake van acuut gevaar voor het kind/de jongere Ouders wilden geen hulp aanvaarden Anders: 'Ouders te zeer onder invloed van middelen'

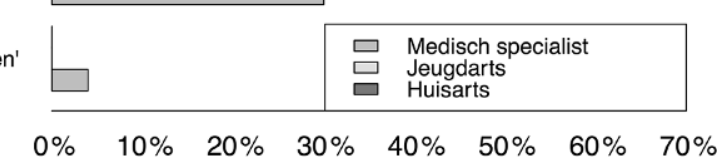

Ervaringen van MP's met Advies- en Meldpunt Kindermishandeling/Veilig Thuis

De meerderheid van de MP's was tevreden over de aanwezige kennis en ervaring, laagdrempeligheid, onafhankelijkheid en onpartijdigheid van VT. De beschikbaarheid van een vertrouwensarts met medischinhoudelijke kennis zagen ze als een grote meerwaarde.

Van de huisartsen en medische specialisten gaf respectievelijk $41 \%$ en $43 \%$ aan voldoende kennis te hebben van de taken en functies van VT, tegenover $63 \%$ van de jeugdartsen.

Als verbeterpunten voor VT werden genoemd: de bereikbaarheid (bij voorkeur 24/7), de lange wachtlijsten, de mogelijkheid om informatie op te vragen, de terugkoppeling na een melding, het beter aansluiten van de geboden hulp bij de verwachtingen van de melder, het bieden van meer hulp bij het oplossen van rolconflicten en het beschikbaar zijn van meer medisch-inhoudelijke kennis binnen VT door de beschikbaarheid van meer vertrouwensartsen, een kinderarts of forensisch arts. De wens tot 24/7-bereikbaarheid van VT kwam ook naar voren uit de landelijke evaluatie van VT door de IGZ [12] en is landelijk inmiddels gerealiseerd.

\section{Richtlijnen binnen de beroepsgroep}

Van de artsen geeft $96 \%$ aan dat er binnen hun vakgebied richtlijnen beschikbaar zijn over de signalering van kindermishandeling en huiselijk geweld, en $89 \%$ bleek hier ook inhoudelijk van op de hoogte te zijn. Tijdgebrek bleek de hoofdreden waarom de artsen niet op de hoogte waren. Daarnaast kozen andere artsen er bewust voor de casus over te dragen aan een collega met expertise.

De overgrote meerderheid (92\%) van de artsen kent de KNMG-meldcode huiselijk geweld en kindermishandeling - $86 \%$ van de medisch specialisten, $71 \%$ van de jeugdartsen en $58 \%$ van de huisartsen maakte er ook gebruik van. In tab. 2 staan redenen aangegeven om af te wijken van deze meldcode.

\section{Ondersteuning}

Alle jeugdartsen en medisch specialisten hadden de beschikking over een duidelijk protocol en over aandachtsfunctionarissen binnen hun organisatie, tegenover respectievelijk $49 \%$ en $28 \%$ van de huisartsen. Alle ziekenhuizen beschikten over een team kindermishandeling, naast respectievelijk $29 \%$ van de jeugdartsen en $15 \%$ van de huisartsen.

\section{Zelfevaluatie en scholing}

Het grootste deel van de jeugdartsen en medisch specialisten beschouwde zichzelf als voldoende competent op het gebied van het signaleren van kindermishandeling en huiselijk geweld, in tegenstelling tot huisartsen (respectievelijk $62 \%$, $62 \%$ versus $45 \%$ ). Van de respondenten die zichzelf niet als voldoende competent beschouwden wenste $83 \%$ aanvullende scholing over onder andere de taken en functies van VT in de vorm van regionale bijeenkomsten, extra e-learnings of aanvullende scholing binnen de opleiding tot basisarts/specialist.

\section{Veilig Thuis-medewerkers}

\section{Kenmerken van de onderzoekspopulatie}

De respons van VT-medewerkers was $87 \%$ (tien maatschappelijk werkenden, twee gedragswetenschappers en één vertrouwensarts). Ze waren gemiddeld negentien jaar werkzaam in de jeugdzorg en werkten gemiddeld negen jaar binnen hun huidige functie.

\section{Indruk van MP's}

De meerderheid van de VT-medewerkers vond dat MP's over het algemeen voldoende weten wat kindermishandeling inhoudt en in staat zijn kindermishandeling te herkennen. Tien van hen $(77 \%)$ hadden de indruk dat MP's de definitie kindermishandeling adequaat interpreteren en $85 \%(n=11)$ vond dat MP's in staat zijn om de verschillende vormen van kindermishandeling te herkennen. Over de kennis van zowel de KNMG-meldcode als de taken en functies van VT was $62 \%(n=8)$ van de respondenten ontevreden. 
Tabel 2 Redenen om af te wijken van de KNMG-meldcode Angst hebben voor de gevolgen voor de relatie met het gezin

Moeite hebben met de signalering van sommige vormen van kindermishandeling

Moeite hebben met het melden zelf

Onduidelijkheid over definitie van kindermishandeling

Zelf een ander traject doorlopen (met ouders en betrokken ketenpartners)

Zich bij een vermoeden van kindermishandeling niet serieus genomen voelen door collega's en daarom niets doen met dit vermoeden

Zorgen hebben om een klacht te krijgen

\section{Ervaringen met MP's}

De communicatie en samenwerking met de MP's werd over het algemeen als redelijk tot goed ervaren.

Vereenvoudigen van het opvragen van medische informatie, verbeteren van de bereikbaarheid van artsen, vergroten van de beschikbare tijd voor een gesprek en het verminderen van vakjargon werden als verbeterpunten genoemd. Bijna alle respondenten $(92 \%, n=12)$ namen zelf geen deel aan bestaande structurele overlegmomenten met MP's en het grootste deel had hier ook geen behoefte aan $(85 \%, n=11)$.

\section{Ervaringen met de vertrouwensarts}

VT-medewerkers vonden dat de inhoudelijke kennis, communicatie met MP's, letselbeschrijving en beoordeling, kennis van wet- en regelgeving, en gespreksvaardigheden van de vertrouwensarts een grote meerwaarde hadden.

\section{Het kwalitatieve onderzoek}

In totaal namen elf medewerkers van VT deel aan het groepsinterview. Hierin werden de resultaten van het kwantitatieve onderzoek kort gepresenteerd en ervaringen met MP's besproken, en werd er bij opvallende bevindingen om een toelichting gevraagd. Zo bleek bijvoorbeeld dat het ontbreken van de behoefte aan structurele overlegmomenten met MP's vooral kwam door de hoge werkdruk en de verplichting om wachttijden te voorkomen. Er bleek wel behoefte te zijn aan deze overlegmomenten.

\section{Beschouwing}

Kindermishandeling komt veel voor. De signalering en aanpak ervan zijn lastig, maar het is de plicht van MP's om bij een vermoeden van kindermishandeling de stappen van de KNMG-meldcode te volgen en al dan niet te melden bij VT.

Uit dit onderzoek blijkt dat medisch specialisten vaker melding doen van kindermishandeling bij VT dan huisartsen en jeugdartsen. Een mogelijke verklaring hiervoor is het verschil in de soort kindermishandeling die het meest wordt gezien in de dagelijkse praktijk. Huisartsen en jeugdartsen zien relatief vaker gevallen van verwaarlozing door hun nauwe betrokkenheid bij een gezin en hebben hierdoor vaak beter zicht op bijvoorbeeld uiterlijke verzorging en interac- tie tussen ouder en kind. Verwaarlozing is vaak een meer structurele vorm van kindermishandeling, waarbij hulp en follow-up in de nulde en eerste lijn vaker al in eigen beheer worden georganiseerd (stap 5a). Hierdoor wordt mogelijk afgezien van een melding bij VT (stap 5b). MP's in een ziekenhuis zijn vaker betrokken bij acute vormen van kindermishandeling, zoals lichamelijke mishandeling en seksueel misbruik. Hierbij zal men eerder overgaan tot een melding. In dit onderzoek hebben MP's in ziekenhuizen tevens de beschikbaarheid over duidelijke protocollen en een team kindermishandeling, hetgeen mogelijk sneller en vaker tot een melding zal leiden.

Een van de redenen om in sommige gevallen af te wijken van de KNMG-meldcode is onduidelijkheid over de definitie van kindermishandeling (tab. 2). De definitie uit de Jeugdwet [13] is breed interpreteerbaar en toepassing ervan wordt beïnvloed door zowel persoonlijke waarden, normen en ervaringen, als culturele verschillen tussen MP's [14]. De in tab. 2 genoemde redenen komen overeen met eerder onderzoek naar barrières die bestaan onder MP's als het gaat om het melden van kindermishandeling [7, 9, 10, 15-17]. Men kan hieruit concluderen dat deze barrières met de huidige aanpak en scholing niet of onvoldoende worden weggenomen. Het invoeren van een meldplicht in plaats van een meldrecht zou voor de meeste MP's in dit onderzoek geen reden zijn om vaker tot melding bij VT over te gaan. Dit laatste komt overeen met bevindingen van eerder gepubliceerde onderzoeken $[16,18]$.

Er is in ons onderzoek sprake van een discrepantie tussen het aantal vermeende meldingen door MP's en de feitelijke cijfers geregistreerd door VT [4]. Er is een overschatting van het aantal eigen meldingen. Dit kan onder andere verklaard worden door de veronderstelling van MP's dat ze een melding gedaan hebben (stap $5 b$ van de meldcode), terwijl er feitelijk sprake was van een advies- dan wel ondersteuningsvraag (stap 2 van de meldcode). Een reden hiervoor kan zijn dat veel MP's aangeven inhoudelijk onvoldoende op de hoogte te zijn van de verschillende taken en functies van VT. Hierdoor wordt de status van een contact met VT mogelijk ten onrechte als melding beschouwd. VT-medewerkers ervaren dit ook zo.

MP's die zich niet competent voelen hebben behoefte aan aanvullende scholing. Dit is opvallend, gezien het grote aantal reeds beschikbare mogelijkheden voor nascholing over kindermishandeling. Wellicht sluit het onderwerp van de huidige scholingen niet goed aan bij de behoeften van de MP's. De meeste scholingen gaan over het signaleren en de aanpak van kindermishandeling, onderwerpen waarvan de meeste MP's goed op de hoogte blijken te zijn. VTmedewerkers ervaren dit ook zo. Het lijkt op basis van de onderzoeksresultaten van dit onderzoek van belang nieuwe scholingen aan te bieden, vooral gericht op informatie over de taken en functies van VT. Op deze manier wordt beter aangesloten op de behoeften 
van de MP's en zal de motivatie om aan de scholingen deel te nemen waarschijnlijk toenemen.

\section{Beperkingen van het onderzoek}

Er is voor gekozen dit onderzoek te richten op de sterke en zwakke punten van de samenwerking en de communicatie tussen MP's en VT in de regio ZuidLimburg. Regionale verschillen kunnen niet worden uitgesloten, ook al werken alle VT-organisaties in Nederland volgens hetzelfde landelijke protocol [19] en volgen alle artsen dezelfde KNMG-meldcode.

Alle VT-medewerkers in de regio Zuid-Limburg, huisartsen, jeugdartsen en alle MP's die met kinderen werken in de ziekenhuizen in Zuid-Limburg zijn benaderd voor het onderzoek. Toch is de onderzoeksgroep klein. Daarom geven wij de resultaten weer in afgeronde percentages en beschouwen we ze als indicatief voor deze groep. Er worden dan ook geen uitspraken gedaan over significantie.

Het responspercentage onder huisartsen is opvallend laag, maar vergelijkbaar met andere, soortgelijke onderzoeken in deze beroepsgroep. Redenen zijn de grote hoeveelheid verzoeken tot deelname aan (wetenschappelijke) onderzoeken en de beperkte tijd die huisartsen hiervoor beschikbaar hebben. Daarom is het mogelijk dat keuze voor deelname aan het huidige onderzoek berust op persoonlijke interesse in het onderwerp en is selectiebias in deze groep respondenten niet uit te sluiten. Dit kan hebben geleid tot een overschatting van onder andere het aantal meldingen bij VT. Mogelijk had het responspercentage vergroot kunnen worden door het belang van het onderzoek via de beroepsvereniging te laten benadrukken.

Recall bias is bij een aantal vragen bovendien niet volledig uit te sluiten, maar de vragenlijst is zodanig ontworpen dat dit risico zo veel mogelijk beperkt blijft.

\section{De toekomst}

Uit literatuuronderzoek blijkt dat er een groot aantal belangrijke aandachtspunten is om tot een betere samenwerking te kunnen komen, zoals het vormen van gemeenschappelijke doelen, wederzijds vertrouwen en respect, duidelijkheid over elkaars rollen en verwachtingen, voldoende evaluatiemomenten en gezamenlijke scholing [20, 21]. Daarnaast is bekend dat het verbeteren van samenwerking tijd kost en vraagt om een structurele langetermijninvestering in de onderlinge relaties [22]. Naar aanleiding van de resultaten van dit onderzoek is er daarom eind 2016 een regulier overleg gestart voor aandachtsfunctionarissen en andere afgevaardigden vanuit de huisartsgeneeskunde, JGZ en VT. Doel van dit overleg is om meer te weten te komen over ieders taken en verantwoordelijkheden, reeds bestaande overlegstructuren en elkaars verwachtingen in geval van een vermoeden van kindermishandeling. Op deze manier wordt aangesloten bij de behoeften van MP's en VT-medewerkers, en zal de samenwerking verbeteren, met als doel het verlagen van de drempel voor MP's om contact op te nemen met VT. Medisch specialisten zijn vooralsnog niet betrokken bij dit overleg, gezien een reeds bestaand regulier overlegmoment tussen het team kindermishandeling in de verschillende ziekenhuizen en VT. Te zijner tijd zal de Provincie Limburg een evaluatie van dit regionale overleg initiëren. Om verder aan te sluiten op de behoeften van de MP's zal er tevens bijscholing georganiseerd worden over de taken en functies van VT, en verschillende aan kindermishandeling en huiselijk geweld gerelateerde onderwerpen.

Vanzelfsprekend is het interessant om in de toekomst het onderzoek te herhalen om te zien of MP's en VT-medewerkers zelf minder drempels ervaren om elkaar te vinden.

\section{Conclusie}

Dit onderzoek heeft de samenwerking en communicatie tussen MP's en VT geëvalueerd. De belangrijkste conclusie is dat zowel MP's als VT-medewerkers over het algemeen tevreden zijn en meer willen weten over elkaars taken, verantwoordelijkheden en verwachtingen, om tot een betere samenwerking en communicatie te kunnen komen. Dit zal worden gerealiseerd door de introductie van reguliere overlegmomenten en het aanbieden van bijscholing aan MP's over onder andere de taken en functies van VT.

Financiering Dit onderzoek werd gesubsidieerd door de Provincie Limburg.

\section{Literatuur}

1. Ministerie van Veiligheid en Justitie. Staatsblad van het Koninkrijk der Nederlanden: Wet van 14 maart2013. 2013.

2. Ministerie van Veiligheid en Justitie. Wet maatschappelijke ondersteuning 2015: artikel5.2.6.2015.

3. Artsenfederatie KNMG. De Meldcode Kindermishandeling en Huiselijk Geweld. Utrecht: Koninklijke Nederlandsche Maatschappij tot bevordering der Geneeskunst (KNMG); 2015.

4. GGDZuid Limburg. Jaarverslag. 2014.

5. Inspectie voor de Gezondheidszorg. Huisartsenposten onvoldoende alert op kindermishandeling. Inventariserend onderzoek naar de kwaliteit van de signalering van kindermishandeling op huisartsenposten. Den Haag: Inspectie voor deGezondheidszorg; 2010.

6. Inspectie voor de Gezondheidszorg. Signalering van kindermishandeling op de huisartsenposten is verbeterd, maar nog niet voldoende. Vervolgonderzoek naar de signalering van kindermishandeling op huisartsenposten. Utrecht: Inspectie voor de Gezondheidszorg; 2012.

7. Burik AE van, Geldorp M. Signaleren en melden van kindermishandeling. Een onderzoek naar kenmerken van (potentiële) melders. DSP:Amsterdam; 1997.

8. Baeten P, Berge I ten, Geurts E, et al. Jonge kinderen in de knel. De aanpakvan kindermishandeling bij 0-tot 4-jarigen onderzocht. Utrecht: Nederlands Instituut voor Zorg en Welzijn; 2001. 
9. Hoefnagels C. Met recht van spreken: enkele theoretische en empirische bijdragen ten behoeve van de secundaire preventie van kindermishandeling. Amsterdam: SWP; 2001.

10. Wolf M. Gevallen of geslagen? Kindermishandeling in de publieke opinie. Amsterdam: NSS/interview; 2004.

11. Nederlands Jeugd instituut. Wegwijs in de Transities van het jeugdstelsel. Utrecht: Nederlands Jeugdinstituut; 2014.

12. Ministerie van VWS. Inspectie Jeugdzorg en Inspectie voor de Gezondheidszorg. De kwaliteit van Veilig Thuis Stap 1 Landelijk beeld. Utrecht: Ministerievan VWS;2016.

13. Ministerie van Volksgezondheid, Welzijn en Sport en ministerie van Veiligheid en Justitie. Wettekst Jeugdwet. Den Haag: Ministerie van VWS en Ministerie van Ven J;2014.

14. Baeten P, Willems J. De maat van kindermishandeling. Meldcode en criteria van kindermishandeling. Amsterdam: SWP;2004.

15. Tiyyagura G, Gawel M, Koziel JR, et al. Barriers and facilitators to detecting child abuse and neglect in general emergency departments. Ann Emerg Med. 2015;66:5.
16. Rossum J van, Wolzak A. Meldplicht kindermishandeling: een toegevoegde waarde? Utrecht: Nederlands Jeugdinstituut; 2008.

17. Ministerie van Volksgezondheid, Welzijn en Sport. Rapportage quickscan meldcode huiselijk geweld en kindermishandeling. Den Haag: Ministerie van VWS; 2015.

18. KNMG. Dreigende aanpassing meldcodekindermishandeling helpt kind in nood niet. Utrecht: KNMG; 2015.

19. Veilig Thuis BP. VNG-Model Handelingsprotocol voor het Advies-en Meldpunt HuiselijkGeweld en Kindermishandeling. Den Haag: Vereniging van Nederlandse Gemeenten; 2014.

20. Berge I ten, Addink A, Baat M de, et al. Stoppen en helpen. Een adequaat antwoord op kindermishandeling. Amsterdam: Nederlands Jeugdinstituut; 2012.

21. Rutte F, Pijpers F, Timmermans M. Samenwerken aan het gezond en veilig laten opgroeien van kinderen. Utrecht: Nederlands Centrum Jeugdgezondheid; 2013.

22. Delden PJ van. Ketensamenwerking: interne krachten bepalen het externe resultaat. Manag Organ. 2010;3:5-20. 